\title{
Pola latihan kuda pacu di Desa Pinabetengan dan Pinabetengan Selatan Kecamatan Tompaso Barat
}

\author{
C. Singal, L.R. Ngangi*, H.F.N. Lapian, S.C. Rimbing \\ Fakultas Peternakan Universitas Sam Ratulangi Manado, 95115 \\ *Korespodensi (corresponding author): Lentjingangi@ gmail.com
}

\begin{abstract}
ABSTRAK
Penelitian ini bertujuan untuk mengetahui pola latihan pada kuda pacu yang ada di desa Pinabetengan dan Pinabetengan Selatan kecamatan Tompaso Barat. Materi penelitian yang digunakan dalam penelitian ini yaitu ternak kuda pacu yang berada di desa Pinabetengan dan Pinabetengan Selatan. Kuda yang dijadikan sampel adalah kuda pacu yang masih aktif. Jumlah sampel yang diambil di desa Pinabetengan Selatan berjumlah 11 ekor, sedangkan di desa Pinabetengan berjumlah 14 ekor. Terjadi perbedaan dalam banyaknya melakukan dan durasi latihan mengunakan pola trot, canter dan gallop di desa Pinabetengan dan Pinabetengan Selatan sedangkan pola walk berlaku sama. Terjadi perbedaan dalam penerapan pola dan latihan diantara desa Pinabetengan dan Pinabetengan Selatan, Pinabetengan cenderung lebih banyak menerapkan latihan harian dengan pola trot, canter dan gallop sedangkan desa Pinabetengan Selatan lebih banyak menerapkan prapacu pola trot, canter dan gallop.
\end{abstract}

Kata Kunci: Kuda pacu, pola latihan, desa Pinabetengan dan Pinabetengan Selatan

\begin{abstract}
RACE HORSE TRAINING PATTERNS IN PINABETENGAN VILLAGE AND SOUTH PINABETENGAN, WEST TOMPASO DISTRICT. This study aims to look at the training patterns of racehorses in Pinabetengan and South Pinabetengan villages, West Tompaso sub-district. The research material used in this study was race horse livestock in Pinabetengan and South Pinabetengan villages. Horses that were sampled were racehorses that were still active. The number of samples taken in South Pinabetengan village was 11 trains, while in Pinabetengan village there were 14 tails. There were differences in the number of exercises and the duration of the exercises using the trot, canter and gallop patterns in Pinabetengan and South Pinabetengan villages while the walking patterns were exactly the same. In the implementation of patterns and exercises between Pinabetengan and South Pinabetengan villages, Pinabetengan tends to apply more daily training with trot, canter and gallop patterns, while South Pinabetengan villages apply more trot, canter and gallop pattern precursors.
\end{abstract}

Keywords: Race horse, exercise pattern, Pinabetengan dan South Pinabetengan village.

\section{PENDAHULUAN}

Kuda adalah salah satu ternak yang telah lama dikembangkan. Akhir-akhir ini di negara maju peternakan kuda telah menjadi industry peternakan untuk kesenangan seperti ketangkasan, pacuan dan hewan kesayangan (Dominguez et al., 2015). Negara-negara Afrika memelihara kuda untuk tenaga kerja (Guyo et al., 2015). Negara Italia mengembangkan ternak kuda untuk pangan berupa daging dan susu (Miraglia et al., 2020). Di Indonesia, kota urban memelihara kuda untuk kesenangan 
sedangkan di daerah pedesaan pemeliharaan untuk kepentingan transpotasi terutama di daerah yang sulit dijangkau dengan kendaraan. Kuda lokal di Indonesia terdiri atas kuda Gayo, kuda Batak, kuda Priangan, kuda Jawa, kuda Sulawesi, kuda Bali, kuda Sumbawa, kuda Flores, kuda Sandel dan kuda Timor (Tulung et al., 2017). Sekitar tahun 1965 dikenal kuda pacu Thoroughbred yang kemudian disilang dengan kuda lokal (kuda Sumba) untuk menghasilkan kuda pacu Indonesia (Soehardjono, 1990)

Kecamatan Tompaso Barat salah satu kawasan di Indonesia Timur yang sudah lama terkenal dengan kuda pacunya. Menurut catatan, sudah sejak tahun 1950-an warga Tompaso terkenal suka memelihara kuda dan biasanya mereka berpacu di Pacuan Maesa Tompaso. Kuda Pacu asal kecamatan Tompaso Barat terkenal sejak lama dikalangan penggemar pacuan kuda dan menjuarai banyak lomba. Bagi yang memiliki kuda pacu yang biasa digunakan untuk berolahraga, wajib memperhatikan latihan rutin dalam mempersiapkan kuda sebelum turun kegelanggang pacuan. Latihan yang diterapkan pada kuda terdiri dari tiga aktivitas yaitu walk, trot, dan canter (Welsch et al., 2014). Waktu latihan, pola latihan serta durasi yang diterapkan oleh para pelatih pada kuda sehari-hari adalah berbeda. Pola latihan dapat berupa walk, trot, canter dan gallop. Latihan-Latihan yang diterapkan akan membuat fisik kuda semakin bagus. Tujuan dari penelitian ini adalah untuk mengetahui pola latihan pada kuda pacu yang ada di desa Pinabetengan dan Pinabetengan Selatan kecamatan Tompaso Barat.

\section{MATERI DAN METODE PENELITIAN}

\section{Waktu dan tempat penelitian}

Penelitian ini telah dilaksanakan pada bulan November sampai dengan Desember 2016 di desa Pinabetengan dan
Pinabetangan Selatan Kecamatan Tompaso Barat Kabupaten Minahasa.

\section{Materi penelitian}

Materi penelitian yang digunakan dalam penelitian ini yaitu 25 ekor ternak kuda pacu aktif dengan perincian 11 dan 14 ekor masing-masing untuk desa Pinabetengan Selatan dan Pinabetengan.

\section{Metode penelitian}

Penelitian ini menggunakan metode survey yaitu pengambilan keterangan secara langsung dengan mewawancarai peternak pemilik ternak kuda pacu menggunakan alat bantu kuisioner.

\section{Teknik pengambilan data}

Pengambilan data dilakukan melalui observasi dan wawancara langsung dengan pemilik kuda pacu menggunakan kuisioner. Penentuan sampel secara purposive sampling yaitu penentuan sampel didasarkan pada karakteristik tertentu yang sudah diketahui sebelumnya yaitu sejumlah peternak yang memiliki kuda siap pacu serta kuda yang sudah pernah ikut perlombaan.

\section{Prosedur penelitian}

Kegiatanpenelitianinibertujuanuntu kmengetahui pola-pola latihan yang baik dan tepat yang diterapkan disetiap stabel, sehingga boleh mendapatkan kuda-kuda yang berprestai.

\section{Variabel Penelitian}

1. Programlatihanharian

2. Programlatihanprapacu

3. Lama durasilatihan harian

4. Lama durasi latihan pra pacu

5. Prestasi kuda dikaitkan dengan pola latihan

\section{Analisa data}

Data yang terkumpul dianalisis secara statistik deskriptif yaitu dengan tabulasi rata-rata sampel, persentase standar deviasi, dan koefisien keragaman (Byrkit, 1987). 
$(\mathrm{sd})=\sqrt{\frac{(\mathrm{X}-\mathrm{X})^{2}}{\mathrm{n}-1}}$

$\overline{\mathrm{X}}=\frac{\sum \mathrm{X}}{\mathrm{n}}$

$\mathrm{KK}=\frac{\mathrm{sd}}{\overline{\mathrm{X}}} \times 100 \%$

Keterangan :

$\mathrm{X}=$ variabel yang diamati

$\overline{\mathrm{X}} \quad=$ Rata-rata variabel yang diamati

$\mathrm{n} \quad=$ Jumlahpengamatanvariabel

$\mathrm{KK}=$ KoefisienKeragaman

\section{HASIL DAN PEMBAHASAN}

\section{Programlatihan harian \\ Walk}

Hasil analisis deskriptif untuk pencapaian angka rerata jumlah latihan harian menggunakan pola walk untuk desa Pinabetengan dan Pinabetengan Selatan masing adalah $2 \pm 0$ kali. Data ini mengambarkan bahwa jumlah (kali) latihan harian kuda pacu menggunakan pola walk yang diterapkan oleh para pelatih didesa Pinabetengan dan Pinabetengan Selatan adalah sama yaitu rata-rata dua kali per hari.

Walk adalah merupakan latihan awal berupa cara berjalan dengan empat ketukan dengan rata-rata sekitar tujuh kilometer per jam. Walk adalah berjalannya kaki kuda mengikuti urutan kaki belakang kiri, kaki kiri depan, kaki belakang kanan, kaki kanan depan dengan ketukan 1-2-3-4 biasa. Saat berjalan, kuda akan bergantian antara tiga atau dua kaki ditanah. Pada level walk, kuda hanya berjalan, penunggang kuda hanya duduk santai sambil mengatur arah dengan tali kekang. Selanjutnya Clayton dan Hobbs (2017) menyatakan bahwa efek dari walk khususnya pada permukaan jalan yang kasar adalah menjadikan tulang kuat dan struktur baik.

\section{Trot}

Hasil analisis deskriptif menunjukkan bahwa angka rerata kuda pacu yang ada di desa Pinabetengan adalah $3,5 \pm 0$ kali sedangkan di desa Pinabetengan Selatan $3 \pm 0$ kali. Data tersebut menggambarkan bahwa kuda pacu yang ada didesa Pinabetengan lebih banyak (0,5 kali) memperoleh latihan harian menggunakan pola trot dibandingkan dengan desa Pinabetengan Selatan. Trot adalah gaya berjalan dua ketukan yang melibatkan sepasang kaki diagonal. Tujuan dari latihan trot adalah untuk menjadikan perototan jantung kuat dan meningkatkan efisiensi dari paru-paru dan diafragma (Hammer dan Champy, 1993). Tujuan dari latihan trot tersebut adalah untuk membiasakan kuda membawa beban dan menguatkan tendon, otot, dan ligamen secara perlahan (Witte, et al. 2006 ; serta Smith, et al 2010).

\section{Canter}

memperoleh latihan harian canter didesa Pinabetengan adalah 2,14 \pm 0,094 kalisedangkan di desa Pinabetengan Selatan1,81 $\pm 0,037$ kali.Data tersebut menggambarkan bahwa kuda pacu yang ada didesa Pinabetengan lebih banyak 0,33 kali memperoleh latihan harian menggunakan pola canter dibandingkan dengan desa Pinabetengan Selatan. Latihan canter secara khusus sangat berguna untuk membangun kekuatan otot, namun perlu dipahami bahwa latihan canter merupakan latihan

Tabel 1. Program Latihan Harian

\begin{tabular}{|c|c|c|c|c|c|c|c|}
\hline \multirow{2}{*}{$\begin{array}{c}\text { Pola } \\
\text { (kali) }\end{array}$} & \multicolumn{3}{|c|}{ Pinabetengan } & \multirow{2}{*}{$\begin{array}{c}\text { Pola } \\
\text { (kali) }\end{array}$} & \multicolumn{3}{|c|}{ Pinabetengan Selatan } \\
\hline & Rerata & $\mathrm{Sd}$ & KK & & Rerata & $\mathrm{Sd}$ & KK \\
\hline Walk & 2 & 0 & 0 & Walk & 2 & 0 & 0 \\
\hline Trot & 3,5 & 0 & 0 & Trot & 3 & 0 & 0 \\
\hline Canter & 2,14 & 0,09 & 4,39 & Canter & 1,81 & 0,03 & 2,04 \\
\hline Gallop & 0,43 & 0,14 & 33,95 & Gallop & 0,54 & 0,12 & 23,14 \\
\hline
\end{tabular}


untuk melangkah secara tidak simetris yang berarti menggunakan otot yang berbeda, tergantung pada canter yang dilakukan apakah canter kiri atau canter kanan. Oleh karena itu kedua sisi otot perlu diseimbangkan khususnya dalam latihan (Hammer dan Champy, 1993). Konsistensi tingkat langkah pada berlari dan canter menunjukkan bahwa kuda individu memiliki frekuensi langkah yang lebih disukai pada kecepatan dan gaya berjalan tertentu. Kuda yang memiliki rasio tinggi antara frekuensi langkah saat berlari dan canter akan cenderung memiliki panjang langkah yang lebih panjang di-canter dengan kecepatan tertentu. Karena kecepatan maksimum berhubungan langsung dengan panjang langkahnya, kuda dengan langkah yang lebih panjang seharusnya memiliki kecepatan puncak yang lebih tinggi dari pada kuda dengan langkah yang lebih pendek (Williams et al., 2009). Menurut Hammer dan Champy (1993) canter secara khusus sangat berguna untuk membangun kekuatan otot, namun perlu dipahami bahwa latihan canter merupakan latihan untuk melangkah secara tidak simetris yang berarti menggunakan otot yang berbeda, tergantung pada canter yang dilakukan apakah canter kiri atau kanan canter. Oleh karena itu kedua sisi otot perlu diseimbangkan khususnya dalam latihan. Pada gaya canter, gerakan kaki juga rendah, pendek, atau panjangnya tergantung pada kecepatan canter yang diinginkan (Blakely dan Bade, 1991).

\section{Gallop}

Tabel 2. Program latihan pra pacu

\begin{tabular}{|c|c|c|c|c|c|c|c|}
\hline \multirow{2}{*}{$\begin{array}{l}\text { Pola } \\
\text { (kali) }\end{array}$} & \multicolumn{3}{|c|}{ Pinabetengan } & \multirow{2}{*}{$\begin{array}{l}\text { Pola } \\
\text { (kali) }\end{array}$} & \multicolumn{3}{|c|}{ Pinabetengan Selatan } \\
\hline & Rerata & $\mathrm{Sd}$ & KK & & Rerata & $\mathrm{Sd}$ & KK \\
\hline Walk & 14 & 0 & 0 & Walk & 14 & 0 & 0 \\
\hline Trot & 3,14 & 0,556 & 17,70 & Trot & 2,5 & 0,271 & 10,66 \\
\hline Canter & 1,57 & 0,26 & 16,62 & Canter & 2,18 & 0,324 & 14,86 \\
\hline Gallop & 1 & 0 & 0 & Gallop & 1 & 0 & 0 \\
\hline
\end{tabular}

Program latihan harian menggunakan pola gallop di desa Pinabetengan memiliki rata-rata $0,43 \pm 0,146$ dan $0,54 \pm 0,125$ untuk desa Pinabetengan Selatan. Ada kecenderungan kuda sampel didesa Pinabetengan Selatan lebih banyak 0,11 kali melakukan latihan harian menggunakan pola gallop dibandingkan dengan desa Pinabetengan.

\section{Program latihan pra pacu}

Pada Tabel 2 menunjukkan rerata latihan pra pacu menggunakan pola walk di desa Pinabetengan dan Pinabetengan Selatan sama yaitu $14 \pm 0$ kali per ekor per minggu. Latihan pra pacu menggunakan pola trot 3,14 $\pm 0,556$ dan 2,5 $\pm 0,271$ masing-masing untuk desa Pinabetengan dan Pinabetengan Selatan. Nilai rerata untuk latihan dengan pola canter yaitu $1,57 \pm 0,26$ untuk desa Pinabetengan dan 2,18 $\pm 0,324$ untuk Pinabetengan Selatan. Untuk pola gallop desa Pinabetengan dan Pinabetengan Selatan memproleh nilai rerata yang sama 1. Hasil latihan pra pacu menggunakan pola trot di desa Pinabetengan lebih banyak 0,64 kali dibandingkan Pinabetengan Selatan. Sebaliknya untuk latihan pra pacu menggunakan pola canter desa Pinabetengan Selatan lebih banyak 0,61 kali dibandingkan desa Pinabetengan.

\section{Prestasi kuda dikaitkan dengan pola latihan}

Faktor latihan termasuk salah satu aspek yang perlu diperhatikan untuk mempersiapkan kuda sebelum turun gelanggang dan menjadikan kuda handal. pengamatan pada Tabel 2 menggambarkan 
Pada umumnya latihan harian dan prapacu yang biasa diberikan yaitu walk, trot, canter dan gallop dengan durasi yang ditentukan oleh pelatih (Rivero et al., 2007; Williams et al., 2009). Selanjutnya Girard et al. (2011) menyatakan pelaksanaan latihan dengan pola yang tepat dapat menentukan tingkat prestasi kuda. Data pengamatan jumlah kuda di desa Pinabetengan dan Pinabetengan Selatan yang pernah menjuarai kejuaraan tertera pada Gambar 1 .

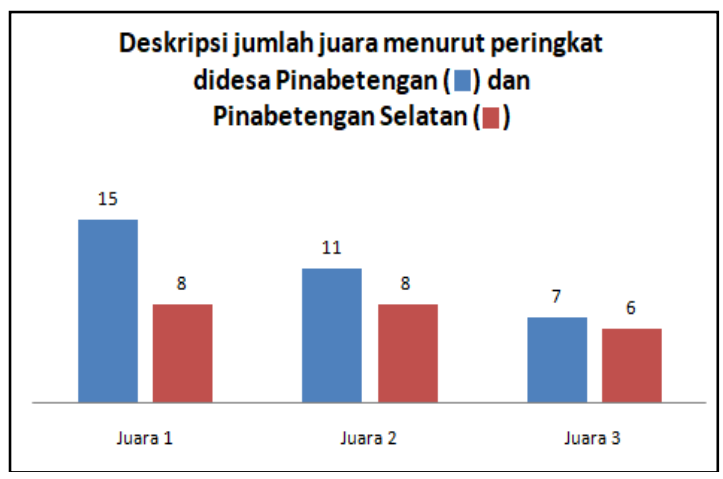

Gambar 1. Capaian Juara Kuda Menurut Peringkat

Pada Gambar 1 menunjukkan angka capaian jumlah juara oleh kuda didesa Pinabetengan yaitu juara satu 15 kali, juara dua 11 kali dan juara tiga sebanyak tujuh kali sedangkan untuk desa Pinabetengan Selatan juara satu, dan dua sebanyak delapan kali dan enam kali untuk juara tiga. Hasil pengamatan ini menunjukkan bahwa prestasi yangdicapai oleh kuda pacu yang ada di desa Pinabetengan lebih baik dibandingkan dengan desa Pinabetengan Selatan, dengan kata lain desa Pinabetengan lebih unggul dalam mencetak kuda juara dalam berbagai peringkat dibandingkan dengan desa Pinabetengan Selatan. oleh kuda pacu sampel yang ada di desa Pinabetengan diduga disebabkan oleh adanya perbedaan dalam hal manajemen pemeliharaan kuda pacu yang ada kaitannya dengan pola latihan harian dan prapacu (jumlah).

Geser-van Painen et al. (2013); Tanner et al. (2013) mengemukakan sempurna atau tidaknya kuda yang ada, membutuhkan antara lain latihan, dan kesehatan fisik yang tepat baginya untuk mewujudkan potensi maksimal. Latihan cepat, pada kondisi ini seharusnya otot, tulang, tendon, dan ligamen kuda sudah terbentuk dengan baik. Pada fase ini pelatihan kuda penekanannya pada sistem pernafasan. Konsistensi tingkat langkah pada berlari dan canter menunjukkan bahwa kuda individu memiliki frekuensi langkah yang lebih disukai pada kecepatan dan gaya berjalan tertentu. Kuda yang memiliki rasio tinggi antara frekuensi langkah saat berlari dan canter akan cenderung memiliki panjang langkah yang lebih panjang di-canter dengan kecepatan tertentu. Karena kecepatan maksimum berhubungan langsung dengan panjang langkahnya, kuda dengan langkah yang lebih panjang seharusnya memiliki kecepatan puncak yang lebih tinggi dari pada kuda dengan langkah yang lebih pendek (Velie et al., 2013; Usherwood, 2020).

\section{KESIMPULAN}

Terjadi perbedaan dalam penerapan pola dan latihan diantara desa Pinabetengan dan Pinabetengan Selatan, Pinabetengan cenderung lebih banyak menerapkan latihan harian dengan pola trot, canter dan gallop sedangkan desa Pinabetengan Selatan lebih banyak menerapkan prapacu pola trot, canter dan gallop.

\section{DAFTAR PUSTAKA}

Blakely, J. dan D.H. Bade. 1995. Ilmu Peternakan, $4^{\text {th }}$ Alih Bahasa: Srigandono, B. dan Soedarsono (Judul Asli The Science Of Animal Hubandry,4th ed.). Gadjah Mada University Press. Yogyakarta. hal 668-669,674, 678-679, 685, 689.

Byrkit, D.R. 1987. Statistic today: A Comprehensive Intoduction. The Benyamin/CummingPublishing Company, Inc. Menlo Park. California. 
Clayton, H. M. dan S.J. Hobbs. 2017. The role of biomechanical analysis of horse and rider in equitation science. Applied Animal Behaviour Science 190: 123-132.

Dominguez, M., S. Münstermann, G. Murray dan P. Timoney. 2015. High health, high-performance' horses: risk mitigation strategies for OIE-listed diseases. Rev. Sci. Tech. 34:837-848.

Geser-von Peinen, K., S.N. Latif, T. Wiestner, C. Bitschnau, B. Renk dan M.A. Weishaupt. 2013. Applied load on the horse's back under racing conditions. The Veterinary Journal 198: 88-92.

Girard, O., J.P. Micallef dan G.P. Millet.2011. Changes in spring-mass model characteristics during repeated running sprint. Eur. J. Appl. Physiol. 111:125-134.

Guyo, S., S. Legesse dan A.Tonamo. 2015. A review on welfare and management practices of working equines. Journal of Animal Science 3(6): 203-209

Hammer, M. dan J. Champy, 1993, Reengineering the Corporation: "A Manifesto For Business Revolution”, Harper Collins Publisher, New York.

Miraglia, N., E. Salimei dan F. Fantuz. 2020. Equine milk production and valorization of marginal areas-A review. Animals 10(2): 353

Rivero, J.L.L., A. Ruz, S. Martí-Korff, J.C. Estepa, E. Aguilera-Tejero, J. Werkman, M. Sobotta dan A. Lindner. 2007. Effects of intensity and duration of exercise on muscular responses to training of thoroughbred racehorses. J. Appl. Physiol. 102: 1871-1882.

Soehardjono, O. 1990. Kuda. Yayasan Pamulang, Jakarta.

Smith, R.K., H. Birch, J. Patterson-Kane, E.C. Firth, L. Williams, W. Cherdchutham, W.R. van Weeren dan A.E. Goodship. 2010. Should equine athletes commence training during skeletal development: Changes in tendon matrix associated with development, ageing, function and exercise. Equine Vet. J. 31(S30): 201-209.

Tanner, J.C., C.W. Rogers dan E.C. Firth. 2013. The association of 2-year-old training milestones with career length and racing success in a sample of Thoroughbred horses in New Zealand. Equine Vet. J. 45(1): 20-24.

Tulung, Y.L.R., L.R. Ngangi dan A.F. Pendong. 2017. Ilmu Ternak Kuda. Bahan Ajar. Fakultas Peternakan. Universitas Sam Ratulangi. Rumah Indih. Manado.

Usherwood, J. R. 2020. An extension to the collisional model of the energetic cost of support qualitatively explains trotting and the trot-canter transition. Journal of Experimental Zoology Part A: Ecological and Integrative Physiology 333(1): 9-19.

Velie, B.D., P.K. Knight, P.C. Thomson, C.M. Wade, N.A. Hamilton. 2013. The association of age at first start with career length in the Australian Thoroughbred racehorse population. Equine Vet. J. 45, 410413.

Welsch, C. E., T.W. Lewis, S.C. Blott, D.J. Mellor, A.J. Stirk dan T.D. Parkin. 2014. Estimates of genetic parameters of distal limb fracture and superficial digital flexor tendon injury in UK Thoroughbred racehorses. The Veterinary Journal 200(2): 253-256.

Williams, R.J., K.J. Nankervis, G.R. Colborne, D.J. Marlin dan R.C. Schroter. 2009. Heart rate, net transport cost and stride characteristics of horses exercising at walk and trot on positive and negative gradients. Comp.

Exerc. Physiol. 6(3): 119.

Witte, T.H., C.V. Hirst dan A.M. Wilson. 2006. Effect of speed on stride parameters in racehorses at gallop in field conditions. J. Exp. Biol. 209, 4389-4397. 